\title{
PERCEPÇÃO ECOLÓGICO-CONSERVACIONISTA DOS FREQUENTADORES DO PARQUE MUNICIPAL CECI CUNHA, ARAPIRACA, ALAGOAS
}

\author{
ECOLOGICAL-CONSERVATIONIST PERCEPTION OF THE USERS OF CECI \\ CUNHA MUNICIPAL PARK, ARAPIRACA, ALAGOAS
} Maria Renata Mariano Silva ${ }^{1}$, Jecilãine Efigênia da Silva², José Wesley Gabriel da Silva ${ }^{3}$, Taynara Alves
de Sousa ${ }^{4}$, Renata Rikelly Silva Barbosa ${ }^{5}$, Jacielle da Costa Santos ${ }^{6}$, Rosineide Nascimento da Silva $^{7}$

\begin{abstract}
RESUMO
O estudo da percepção ambiental é importante para a compreensão das inter-relações entre o homem e o ambiente. Assim, o objetivo deste estudo foi analisar e percepção ecológico-conservacionista dos frequentadores do Parque Municipal Ceci Cunha, localizado no município de Arapiraca, Alagoas. A coleta de dados ocorreu por meio da aplicação de questionário a 100 frequentadores, entre os meses de abril e maio de 2019. Os dados foram organizados em tabelas e gráficos no programa Microsoft Excel for Windows ${ }^{\circledR}$ e a análise realizada por meio de estatística descritiva. Verificou-se que: a maioria dos entrevistados era do sexo masculino (56\%); a faixa etária variou entre 13 anos e 65 anos de idade; e os frequentadores apresentaram diferentes níveis de escolaridade. Quanto à percepção ecológicoconservacionista, quase todos os entrevistados consideram a presença de arborização um elemento importante para o meio urbano; a maior parte dos usuários considerou que o Parque Municipal Ceci Cunha não está em boas condições de conservação; a maioria pratica ações que ajudam na conservação desse espaço público, como o descarte adequado do lixo, entre outros. As informações obtidas sobre a percepção ambiental dos frequentadores do Parque são relevantes para nortear as políticas públicas.
\end{abstract}

Palavras-chave: Arborização; Conservação; Usuários; Espaço público; Cidade.

\section{ABSTRACT}

The study of environmental perception is important for understanding the interrelationships between man and the environment. Thus, the objective of this study was to analyze the ecological-conservationist perception of the users of Ceci Cunha Municipal Park, located in Arapiraca, Alagoas. Data were collected by applying a questionnaire to 100 users between April and May 2019. Data were organized in tables and graphs using the Microsoft Excel for Windows ${ }^{\circledR}$ program and the analysis was performed using descriptive statistics. It was found that: the majority of interviewees were male $(56 \%)$; the age range varied from 13 years to 65 years old; and the users had different levels of education. As for the ecological-conservationist perception, almost all interviewees consider the presence of trees an important element for the urban environment; most users considered that Ceci Cunha Municipal Park is not in good conservation condition; most practice actions that help in the conservation of this public space, such as proper discard of garbage, among others. The information obtained on the environmental perception of Park users is relevant to guide public policies.

Keywords: Urban trees; Conservation; Users; Public space; City.

Recebido em 07.08.2019 e aceito em 22.10.2019

1 Aluna do Curso de Ciências Biológicas. Universidade Estadual de Alagoas. Arapiraca/AL. Email: marianorenataz73@gmail.com 2 Aluna do Curso de Ciências Biológicas. Universidade Estadual de Alagoas. Arapiraca/AL. Email: jecilaine16@gmail.com 3 Aluno do Curso de Ciências Biológicas. Universidade Estadual de Alagoas. Arapiraca/AL. Email: gabrielwess2@gmail.com 4 Aluna do Curso de Ciências Biológicas. Universidade Estadual de Alagoas. Arapiraca/AL. Email: taynara.sousa1298@gmail.com 5 Aluna do Curso de Ciências Biológicas. Universidade Estadual de Alagoas. Arapiraca/AL. Email: rrenatab.27@gmail.com 6 Aluna do Curso de Ciências Biológicas. Universidade Estadual de Alagoas. Arapiraca/AL. Email: costajacielle@gmail.com 7 Bióloga licenciada. Mestra em Ecologia e Conservação. Docente da Universidade Estadual de Alagoas. Arapiraca/AL. Email: rosineideg7@gmail.com 


\section{INTRODUÇÃO}

Nas cidades, as áreas verdes urbanas e, especialmente os parques públicos surgem como "espaços de natureza", em geral, criados e fundamentados no discurso do lazer, da qualidade de vida e da qualidade ambiental (GOMES, 2013). Estes espaços, segundo Herzog e Rosa (2010), são responsáveis por serviços ecossistêmicos significativos, como a purificação do ar e da água, a retenção de poluição sonora, a estabilização do microclima, além de serviços sociais e psicológicos, proporcionados pelo contato com o "verde".

Em geral, os parques urbanos passaram por várias transformações entre as décadas de 1970 e 1980, destacando-se as suas diferentes funções sociais e incorporando características socioambientais, como o lazer e a recreação, além da conservação da natureza (AMADOR, 2012). Nesse contexto, os parques urbanos se inserem no imaginário social como sendo lugares de lazer, que contém áreas verdes e propiciam qualidade de vida para os citadinos que, quando públicos, devem ser acessíveis para todos, independentemente da classe social (GOMES, 2013).

Garvin (2011) destaca que a origem dos parques urbanos remonta aos séculos XVII e XVIII, principalmente, a partir do término da Revolução Francesa, quando propriedades da família real ou de nobres europeus foram abertas ao público para fins recreativos. Segundo o autor, jardins reais e áreas de caça, destinados ao usufruto de poucos, foram transformados em parques públicos e tornaram-se os precursores dos atuais parques urbanos.

As áreas verdes urbanas, como espaços livres de construção, podem reforçar a ideia de conservação e preservação da biodiversidade, sendo capazes de influenciar a qualidade ambiental e, consequentemente, a qualidade de vida das pessoas. Assim, o planejamento e a gestão ambiental dessas áreas urbanas devem levar em consideração a necessidade de incluir a figura do cidadão nesses espaços como fator primordial para a difusão de uma sensibilidade ambiental (PINA; SANTOS, 2012).

De acordo com Nasir, Ahmad e Ahmed (2016), grandes espaços verdes valorizam o ambiente e a estética das cidades, além de constituírem um meio para atividades da comunidade, criando oportunidades de recreação e educação pelo contato com a natureza, mesmo que de forma antropizada. Os mesmos autores citam que estas áreas também atraem investimentos, turismo e geram empregos, além de oferecerem localização ideal para a prática de atividades físicas, que contribuem para o aumento da qualidade de vida humana.

Estudos de percepção ambiental possuem grande importância para a compreensão das inter-relações entre o homem e o ambiente. Percepção ambiental pode ser definida como uma tomada de consciência, por parte dos indivíduos, sobre o meio em que se encontram inseridos, aprendendo a respeitar, a proteger e a cuidar (CARVALHO, 2010). 
A compreensão da percepção ecológica, portanto, pode ser um importante fator para a conservação ou manutenção das áreas verdes, seja para sua melhoria como um todo, seja para sua ampliação, proteção e/ou promoção como forma de garantir às comunidades um espaço agradável de convívio social (SILVA; CÂNDIDO; FREIRE, 2009). Esses autores ainda destacam que, saber interpretar a percepção ambiental é um desafio para a adequação e melhor funcionalidade das áreas verdes, pois as populações que residem próximas a esses espaços possuem conhecimento sobre seus recursos e problemas enfrentados, podendo apontar soluções que possibilitem aliar as práticas de gestão e estratégias de conservação.

Partindo de tais considerações, este estudo foi realizado com o objetivo de analisar a percepção ecológico-conservacionista dos frequentadores do Parque Municipal Ceci Cunha, localizado no município de Arapiraca-AL. A análise dessa percepção foi correlacionada com o perfil sociodemográfico e com os hábitos de utilização desse espaço público pelos frequentadores.

\section{MATERIAL E MÉTODOS}

\section{Local da pesquisa}

Arapiraca (945'09" S 36³9'40" O), município localizado no interior do Estado de Alagoas, está situado no Agreste alagoano (Figura 1), tem população estimada em 230.417 habitantes e ocupa uma área de $345,65 \mathrm{Km}^{2}$ (IBGE, 2018). O município possui altitude aproximada de $264 \mathrm{~m}$; clima tropical chuvoso com verão seco; precipitação pluviométrica com média anual de $1.634 \mathrm{~mm}$; vegetação predominante de Floresta Subperenifólia, com partes de Floresta Subcaducifólia e Cerrado/Floresta (MASCARENHAS; BELTRÃO; SOUZA-JÚNIOR, 2005).

Integrando a zona urbana e central de Arapiraca, está o Parque Municipal Ceci Cunha (Figura 2A), cuja criação perpassa por uma história de ocultação (aterramento da área da Lagoa das Olarias, canalização e ocultação das águas poluídas do riacho Piauí) e recriação de elementos da natureza (gramado, jardins, lagos artificiais), desde a década de 1990, sendo suas etapas mais recentes concluídas nos anos de 2006 e 2007, totalizando uma área de $11.000 \mathrm{~m}^{2}$ (SILVA; GOMES, 2010; 2013). 

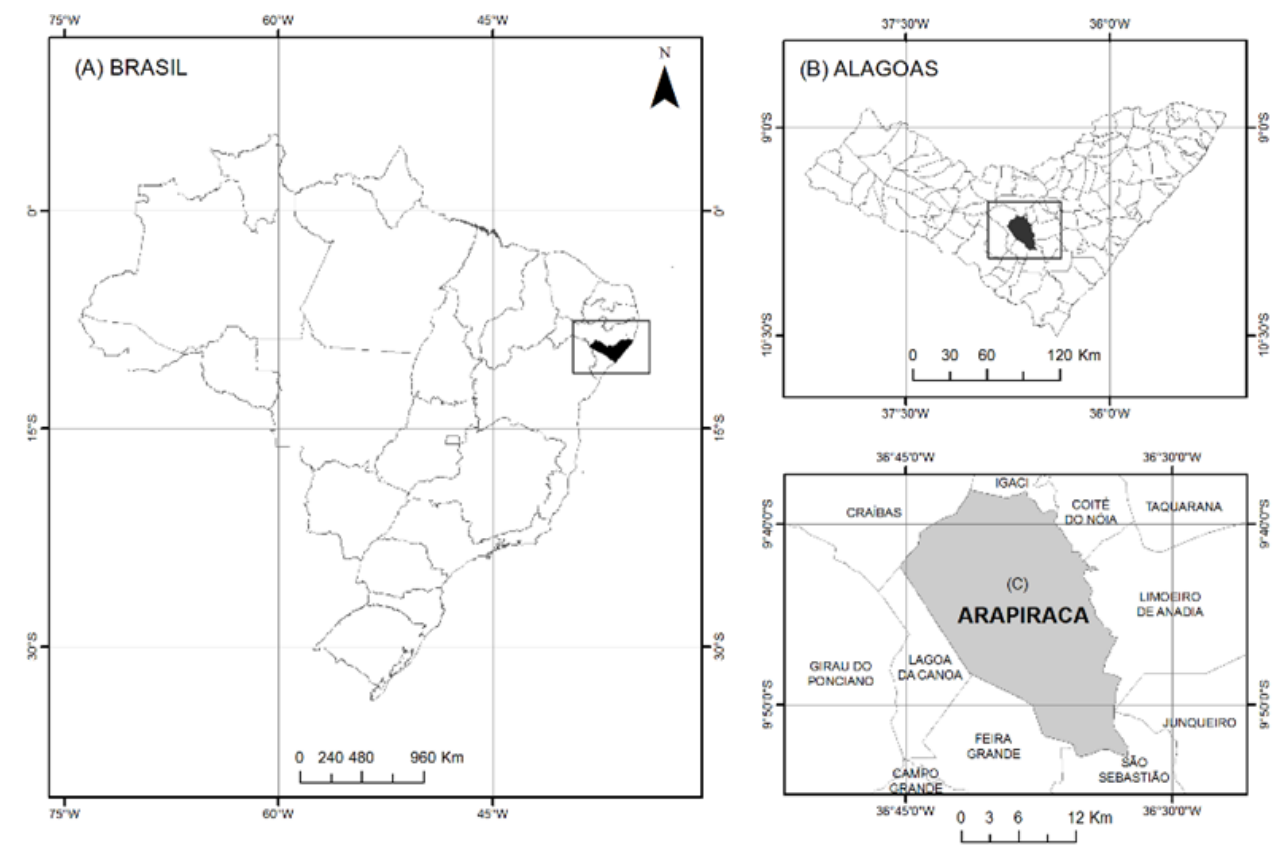

Fonte: Gomes, Silva e Ferreira (2015)

Figura 1. Localização do Estado de Alagoas no Brasil (A), destacando-se o município de Arapiraca (B) Figure 1. Location of the State of Alagoas in Brazil (A), highlighting the municipality of Arapiraca (B)

De acordo com Gomes Júnior (2016), a primeira etapa do parque chama-se Parque Municipal Ceci Cunha I, a segunda, Parque Municipal Ceci Cunha II e, a última, chama-se Mercado do Artesanato Margarida Gonçalves (Figura 2B). Segundo esse autor, há uma visível distinção entre as etapas, já que é notável a falta de manutenção na maior parte da etapa I, por exemplo, quando comparada às demais.
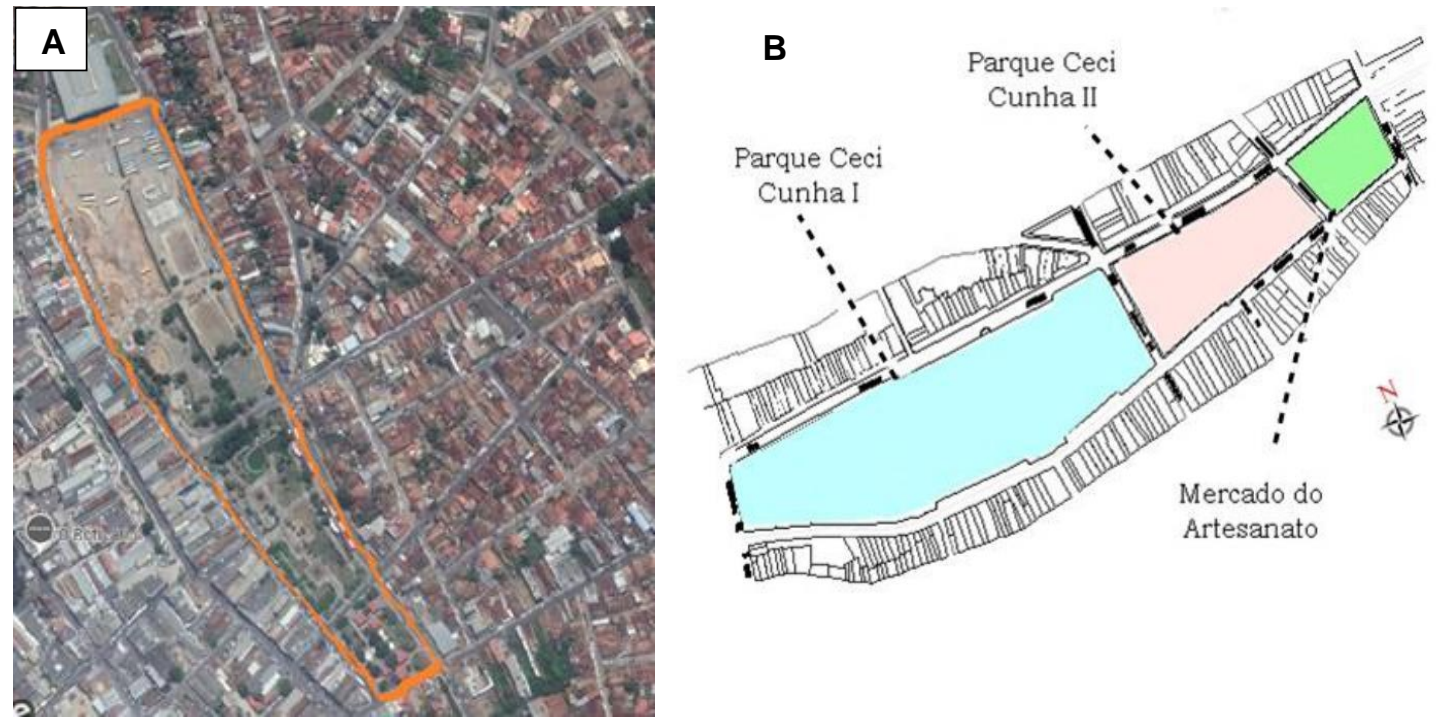

Fonte: (A) Adaptado do Google Maps (2019); Fonte: (B) Gomes Júnior (2016).

Figura 2. Detalhe do delineamento $(A)$ e representação, sem escala, das três etapas (B) do Parque Municipal Ceci Cunha, em Arapiraca-AL

Figure 2. Detail of the design $(A)$ and representation, without scale, of the three stages (B) of Ceci Cunha Municipal Park, in Arapiraca-AL 


\section{Coleta e análise dos dados}

A pesquisa foi realizada entre os meses de abril e maio de 2019. A coleta de dados ocorreu por meio da aplicação de questionário (Figura 3), que conforme Gil (2011), é uma das práticas de coleta de dados mais usadas por ser bastante adequada para se obter informações acerca do que as pessoas sabem, creem ou esperam, bem como sobre suas explicações ou razões a respeito das coisas anteriores.

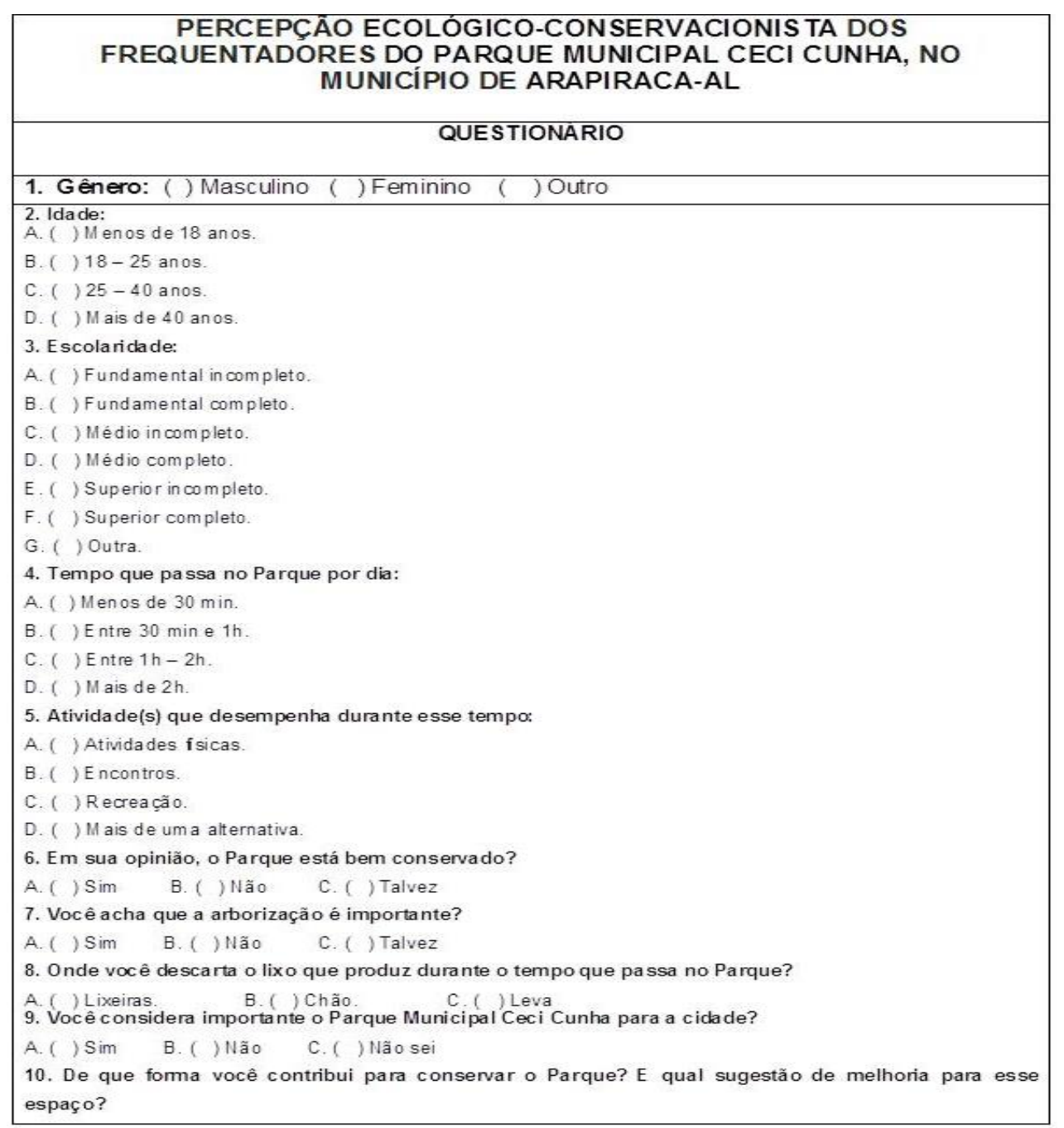

Figura 3. Questionário aplicado aos frequentadores do Parque Municipal Ceci Cunha, em Arapiraca-AL Figure 3. Questionnaire applied to users of Ceci Cunha Municipal Park, in Arapiraca-AL

O questionário, composto por 10 questões, foi organizado de modo que contemplasse informações relacionadas ao perfil sociodemográfico, aos hábitos de utilização do Parque Municipal Ceci Cunha e a percepção ecológico-conservacionista dos frequentadores. As questões referentes ao perfil sociodemográfico foram: sexo, faixa etária e escolaridade. Quanto 
às variáveis relativas aos hábitos de utilização do Parque, foram consideradas: tempo de permanência e forma de utilização do espaço. E por último, as variáveis relacionadas à percepção ecológico-conservacionista, foram: estado de conservação do Parque, relevância da arborização, local de descarte do lixo produzido pelos usuários desse espaço, importância do Parque para os entrevistados, ações de conservação desempenhadas pelos frequentadores e, sugestões de melhorias indicadas pelos entrevistados.

O questionário foi aplicado a 100 frequentadores, conforme a técnica de amostragem não probabilística e por acessibilidade ou conveniência dos usuários em participar da pesquisa. Apesar da amostra não ter sido probabilística, o quantitativo de 100 entrevistados torna-se uma amostra representativa ao nível de $95 \%$ de confiança, com margem de erro de $10 \%$, considerando-se que a população de Arapiraca é estimada em 230.417 habitantes. O critério de inclusão dos participantes foi, essencialmente, ser frequentador do Parque Municipal Ceci Cunha e possuir mais de 13 anos de idade. Foi considerado frequentador, o usuário que estava praticando caminhada, corrida, contemplação da paisagem, ou qualquer outra atividade de uso do espaço público, sem restrições, conforme recomendam Zardin et al. (2017).

Além disso, foram selecionados alguns horários em diferentes dias, inclusive fins de semana, para a aplicação do questionário. Assim, as entrevistas foram efetuadas nos seguintes horários: 08:00-11:00h, 14:30-16:00h e 17:00-19:00h. Além disso, durante a aplicação dos questionários, foram realizadas algumas observações gerais in loco.

Os dados coletados foram organizados em tabelas e gráficos utilizando-se o programa Microsoft Excel for Windows ${ }^{\circledR}$. A análise dos dados foi realizada por meio de estatística descritiva e estruturada em seções, de acordo com a metodologia adaptada de Zardin et al. (2017): perfil sociodemográfico dos frequentadores, hábitos de utilização do Parque e percepção ecológicoconservacionista dos frequentadores.

\section{RESULTADOS E DISCUSSÃO}

\section{Perfil sociodemográfico}

A maioria dos frequentadores era do sexo masculino (56\%) (Tabela 1), resultado semelhante ao encontrado em outros estudos, que apontam uma maior frequência do público masculino quando comparado ao feminino (BRUN et al., 2010; GOMES JÚNIOR, 2016; ZARDIN et al., 2017). 
Tabela 1. Perfil dos frequentadores do Parque Municipal Ceci Cunha, em Arapiraca-AL

Table 1. Users' profile of Ceci Cunha Municipal Park, Arapiraca-AL

\begin{tabular}{c|c|c}
\hline VARIÁVEIS & DESCRIÇÃO & FREQUÊNCIA (\%) \\
\hline \multirow{3}{*}{ Gênero } & Masculino & 56,0 \\
& Feminino & 42,0 \\
& Outros & 2,0 \\
\hline \multirow{4}{*}{ Idade } & Menos de 18 anos & 7,0 \\
& 18 a 25 anos & 25,0 \\
& 25 a 40 anos & 27,0 \\
& Mais de 40 anos & 41,0 \\
\hline \multirow{5}{*}{ Escolaridade* } & EFC & 9,0 \\
& EFI & 24,0 \\
& EMC & 19,0 \\
& EMI & 20,0 \\
& ESC & 6,0 \\
& ESI & 15,0 \\
& Outros & 7,0 \\
\hline
\end{tabular}

*Legenda: EFC: Ensino Fundamental Completo; EFI: Ensino Fundamental Incompleto; EMC: Ensino Médio Completo; EMI: Ensino Médio Incompleto; ESC: Ensino Superior Completo; ESI: Ensino Superior Incompleto.

Com relação à idade e à escolaridade dos indivíduos que participaram da pesquisa, a faixa etária variou de 13 a 65 anos, sendo que a maioria apresentou mais de 40 anos de idade (41\%). A escolaridade dos frequentadores foi dispersa em diferentes níveis, variando desde o ensino fundamental incompleto até o ensino superior, sendo que os que possuíam ensino fundamental incompleto totalizaram $24 \%$ (Tabela 1). Tanto a amplitude da faixa etária quanto da escolaridade verificada se assemelhou, parcialmente, por exemplo, ao estudo de Pizziolo et al. (2014), pois os autores constataram que seus entrevistados tinham idade entre 18 e mais de 40 anos, com nível de instrução variável, indo desde analfabetos até usuários com ensino superior completo.

De acordo com Barros et al. (2018), os espaços públicos tonam-se, cada vez mais, espaços de utilização comum, independentemente do sexo, da idade e do nível de instrução de seus frequentadores, o que pode ser explicado pelos benefícios relativos à qualidade de vida que esses espaços podem proporcionar à população. Por outro lado, sabe-se que os parques, especificamente, tanto podem ser considerados elementos que glorificam a natureza, quanto se revelam como objetos que introduzem novos desejos, dinâmicas e intencionalidades no espaço urbano, não sendo meros elementos inócuos na paisagem (GOMES, 2013). 


\section{Hábitos de utilização do Parque Municipal Ceci Cunha}

Em relação ao tempo que os frequentadores permanecem no Parque, grande parte (40\%) alegou que passa mais de duas horas, enquanto $28 \%$ dos usuários informaram que permanecem menos de 30 minutos (Tabela 2). Gomes Júnior (2016), em seu estudo realizado em 2016, também no Parque Municipal Ceci Cunha, porém com um esforço amostral de apenas 25 entrevistas, constatou que a maioria dos frequentadores $(60 \%)$ permanece até uma hora nesse Parque, diferente do que foi registrado aqui. Contudo, deve-se atentar que, ao longo de três anos, o referido Parque pode ter passado por alterações relevantes que propiciaram o aumento da permanência de seus usuários como, por exemplo, o crescimento do componente arbóreo que pode ter favorecido as condições microclimáticas, tornando-se um lugar mais agradável para seus frequentadores.

Tabela 2. Tempo que os frequentadores permanecem no Parque Municipal Ceci Cunha, em Arapiraca$\mathrm{AL}$

Table 2. Time that users stay in the Ceci Cunha Municipal Park, in Arapiraca-AL

\begin{tabular}{cc}
\hline PERMANÊNCIA NO PARQUE & FREQUÊNCIA (\%) \\
\hline Menos de 30 minutos & 28 \\
30 minutos -1 hora & 12 \\
1 hora -2 horas & 20 \\
Mais de 2 horas & 40 \\
\hline
\end{tabular}

Permanências longas, aqui consideradas como mais de uma hora, podem revelar as potencialidades, os significados e os valores desse Parque para a população frequentadora, que depende desse espaço público para a prática de determinadas atividades.

Ao observar as atividades desempenhadas pelos frequentadores durante o tempo que permanecem no Parque, pôde-se observar a relação entre essas atividades e o dia da semana que os usuários estavam nesse espaço, ou seja, o número de entrevistados que praticam atividades físicas, sobressaiu-se durante a semana, enquanto que a recreação e os encontros se destacaram nos finais de semanas. Contudo, deve-se notar que $25 \%$ dos frequentadores entrevistados, conjuntamente, apresentaram mais de uma forma de utilização desse Parque, enquanto que $75 \%$ deles alegaram usá-lo para a prática de atividades físicas, encontros e recreação (Figura 4), tendo em vista seus aspectos gerais, tanto estético-paisagísticos quanto de infraestrutura.

Para Zardin et al. (2017), o lazer e a recreação compreendem atividades como caminhar, passear, namorar, etc., ao passo que as atividades físicas representam a busca pela saúde e pelo bem-estar. Baseados em seu estudo, esses autores, perceberam que os frequentadores de espaços públicos estão cada vez mais em busca de qualidade de vida, dando 
a entender que uma forma de encontrá-la é em parques. Essa, comprovadamente, pode ser a concepção apresentada pelos entrevistados neste estudo.

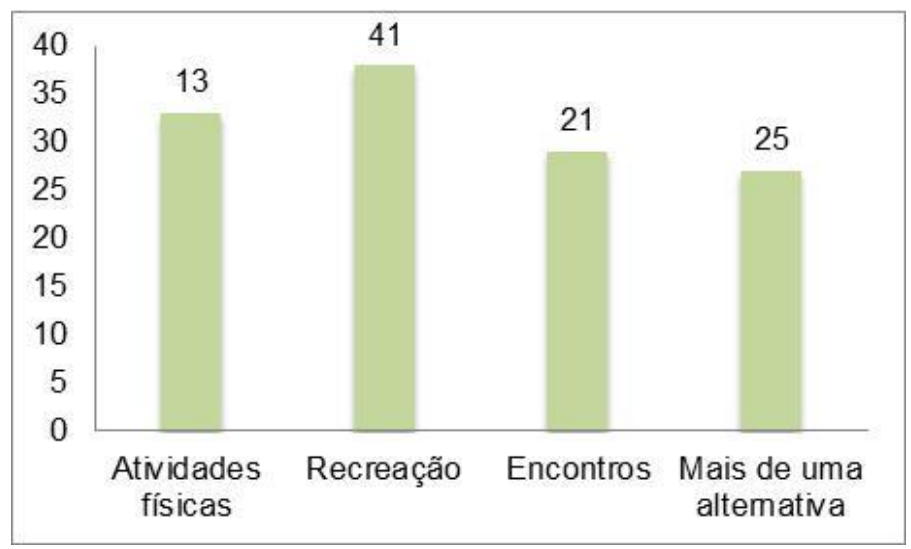

Figura 4. Formas de utilização do Parque Municipal Ceci Cunha, em Arapiraca - AL, pelos frequentadores Figure 4. Ways of using the Ceci Cunha Municipal Park, in Arapiraca - AL, by the users

De acordo com Ferreira (2007), a rotina cansativa imposta pela vida urbana, pode ser abatida por atividades realizadas nos parques, como caminhadas, passeios e brincadeiras, além da possibilidade de convivência entre os moradores das cidades nesses espaços. E esses benefícios, unidos ao lazer, também estão próximos à função psicológica de aliviar o estresse. Deve-se considerar que, os espaços públicos, de modo geral, podem ser compreendidos como equipamentos importantes, não apenas quanto ao valor estético e de conservação ambiental, mas, sobretudo, por apresentarem potencial, se debatidos com a sociedade, para o desenvolvimento de alternativas mais democráticas de lazer, carência expressiva das cidades brasileiras (GOMES, 2013).

É perceptível que, quanto mais abrangente as formas de uso de um espaço público, mais as pessoas são atraídas. Por outro lado, quando as pessoas deixam de frequentar determinado espaço público, o mesmo tende a se tornar esquecido pela gestão pública e, assim, torna-se cada vez mais menos frequentados pelas pessoas, culminando em um espaço depredado, maltratado e sem uso, seja pela falta de segurança seja pela manutenção precária de seus equipamentos (GOMES JÚNIOR, 2016).

A conservação de áreas construídas ou naturais está intimamente relacionada ao uso que a população faz desses espaços que, ao entrar em contato direto com a natureza, a partir do uso dessas áreas, os frequentadores desenvolvem sensações e percepções que permitem o surgimento de laços afetivos com as mesmas, já que possibilitam diferentes experiências, relações sociais, atitudes e emoções/sentimentos (PEREIRA; SIMONETTI, 2012; SILVA et al., 2013). 


\section{Percepção ecológico-conservacionista dos frequentadores}

A maioria dos participantes da pesquisa (57\%) considerou que o Parque Municipal Ceci Cunha não está em bom estado de conservação, 27\% informaram que o Parque está em bom estado de conservação e 16\% não opinaram. Todavia, saliente-se que, o estado de conservação de um espaço público atua como o reflexo da aceitação ou rejeição dele pelos frequentadores, o que reflete no atendimento ou não de seus desejos (GOMES JÚNIOR, 2016).

Quanto à importância da arborização, quase todos os entrevistados (93\%) a considerou importante para o meio urbano, mas 4\% disseram que a arborização talvez seja importante e 3\% não a considerou importante. A partir desse resultado, pode-se inferir que, para a maior parcela dos frequentadores, a arborização pode contribuir com o sombreamento, o conforto térmico devido a redução do calor, o ar puro e a estética do local que podem ser garantidos pela manutenção das árvores, conforme defendem Barros et al. (2018) e Almeida, Gêa e Siqueira (2019). Atribuir importância à arborização urbana por parte de frequentadores de um parque pode ser um indicativo de sensibilidade ambiental das pessoas quanto à relevância e as contribuições que a vegetação pode proporcionar para os citadinos, em geral.

Por outro lado, Pizziolo et al. (2014) destacam que a população não possui conhecimento sobre todos os benefícios que a arborização pode trazer para a qualidade de vida no perímetro urbano, só conseguindo reconhecer a formação de sombra e a redução do calor; mas, ainda assim, destacam que é de fundamental importância a percepção da população. Além disso, as vantagens da arborização que consistem no fornecimento de sombra e na redução do calor evidenciam que os moradores sentem a necessidade de melhoria do microclima e do conforto térmico no meio urbano (ROPPA et al., 2007).

Destaque-se que, há fatores importantes que devem ser considerados quando da implantação da arborização em espaços públicos como, por exemplo, a valorização e o planejamento dessa arborização perpassam pela seleção de espécies regionais endêmicas, pelas melhorias na infraestrutura desses espaços e pelos investimentos em capacitação de técnicos da prefeitura (BARROS et al., 2018).

No que tange ao descarte do lixo produzido pelos frequentadores, $69 \%$ dos entrevistados informaram que o descartam em lixeiras. Entretanto, ainda se nota a carência de maior sensibilidade dos usuários do Parque, pois $11 \%$ têm o hábito de descartar o lixo no chão (Figura 5). Mesmo que a maior parte dos entrevistados tenha alegado que descarta o lixo na lixeira, durante o período da pesquisa, verificou-se que no Parque havia muito lixo residual descartado no chão, o que pode corroborar com o que os $11 \%$ dos frequentadores citaram. $A$ esse respeito, cabe ressaltar o que Martinez (2012) frisa, pois para o autor, algumas pessoas, aparentemente, não se sentem responsáveis pelo cuidado com o ambiente (neste caso, 
responsáveis pelos próprios resíduos produzidos), não atribuindo responsabilidades para si próprias.

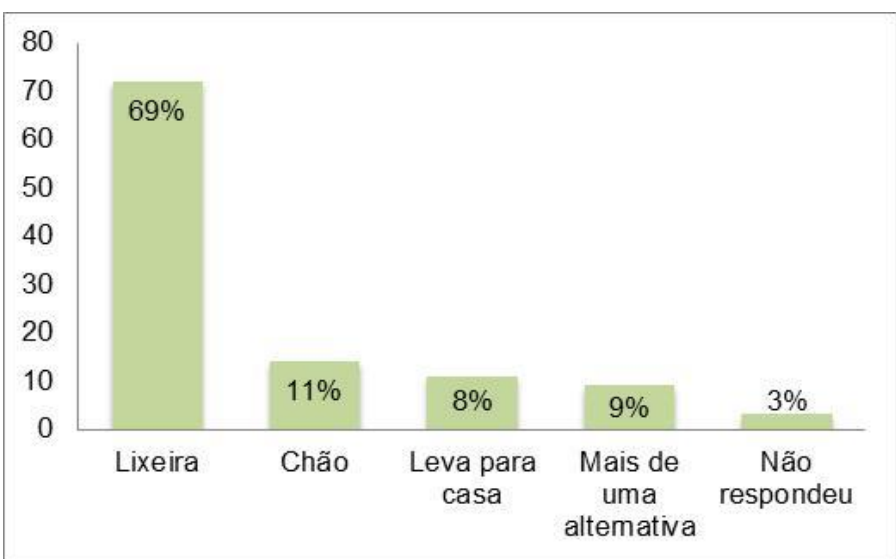

Figura 5. Formas de descarte do lixo produzido pelos frequentadores do Parque Municipal Ceci Cunha, em Arapiraca-AL

Figure 5. Ways of discarding the garbage produced by the users of Ceci Cunha Municipal Park, in Arapiraca-AL

Como variáveis que podem afetar ou não o comportamento humano, tem-se tanto a consciência das consequências que uma ação individual (ou uma omissão) pode trazer para o bem-estar coletivo, quanto a atribuição de responsabilidade para si mesmo, controlando uma determinada ação e seus resultados (MARTINEZ, 2012). Para esse autor, a partir do senso de responsabilidade, o qual fundamenta a expressão de comportamentos, pode-se ter condutas mais favoráveis e conscientes quanto a manutenção do ambiente.

Acredita-se que a limpeza de um espaço público pode ser um fator determinante para que o mesmo seja visto como com condições adequadas para o uso pelos seus frequentadores, pois esse fator contribui tanto com os aspectos estético-paisagísticos quanto com a sensação de salubridade do local, o que pode despertar o interesse dos usuários em desempenhar diferentes atividades.

Os frequentadores também foram questionados sobre a importância do Parque Municipal Ceci Cunha para a cidade de Arapiraca-AL. Todos os entrevistados corroboram a importância desse espaço público, visto como um ambiente agradável dentro do centro urbano e que pode proporcionar lazer ao público, por exemplo. Essa informação foi ratificada por Gomes Júnior (2016), já que 96\% dos frequentadores entrevistados pelo autor também consideraram o Parque importante, mencionando que a implantação desse espaço público foi um marco para a cidade de Arapiraca, já que favorece o encontro de pessoas, o descanso, a contemplação da natureza e a prática de esportes, além de ser um lugar bonito e que atua na divulgação da cultura local através de apresentações e eventos culturais. 
Ao indagar os entrevistados em relação às ações que eles praticam e que ajudam na conservação do Parque, a maioria (77\%) afirmou que costuma descartar o lixo corretamente e $14 \%$ costumam plantar mudas, regar plantas, cuidar dos animais presentes no local e zelar pelo patrimônio público, embora não tenham especificado como seria esse zelo ou cuidado (Figura 6). Um fato interessante que se observa é que para $77 \%$ dos entrevistados, o simples ato de jogar o lixo em local apropriado, ou seja, em lixeiras, é considerado pelos frequentadores uma "ação de conservação" quando, na verdade, trata-se de um ato de educação.

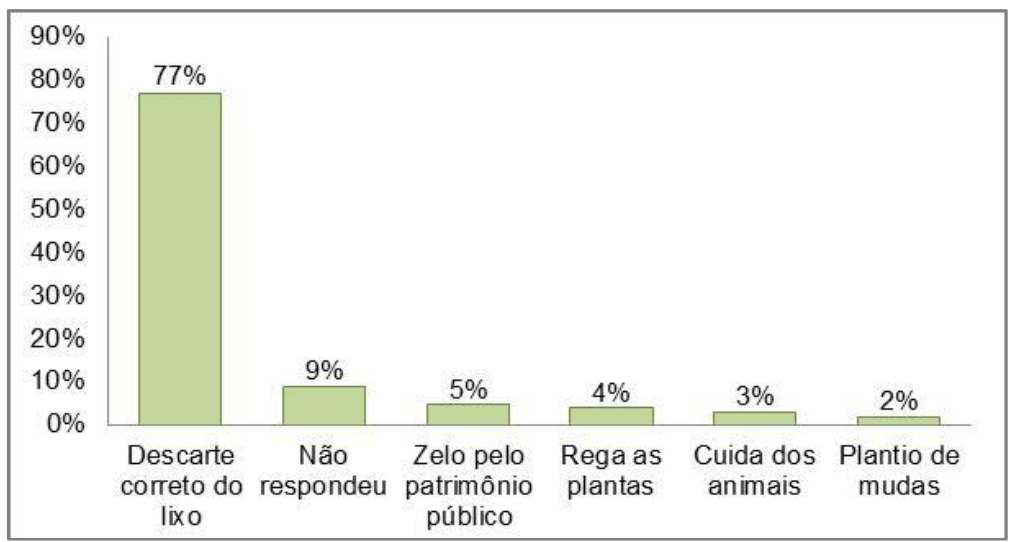

Figura 6. Principais ações de conservação praticadas pelos frequentadores do Parque Municipal Ceci Cunha, em Arapiraca-AL

Figure 6. Main conservation actions practiced by the users of Ceci Cunha Municipal Park, Arapiraca-AL

Silva e Gomes (2010) afirmaram, em um estudo realizado no Parque Municipal Ceci Cunha, que apesar deste local ser importante na cidade, em termos de lazer ativo e contemplativo, o mesmo apresenta limitações no que tange à prática da conservação e da educação ambientais, tendo em vista que não foi planejado com esse intuito, especificamente.

Os frequentadores foram ainda questionados sobre sugestões de melhorias para 0 Parque para que, assim, pudessem realizar suas atividades com mais qualidade. Foram registradas diversas sugestões, porém sobressaiu-se a questão da necessidade de mais segurança (27\%) (Figura 7). A segurança é um elemento importante, pois as pessoas tendem a frequentar lugares onde se sentem seguras ou protegidas e, assim, atraem-se mais pessoas (GOMES JÚNIOR, 2016). Esse autor percebeu que apenas a terceira etapa do Parque Municipal Ceci Cunha, que abriga o Mercado de Artesanato Margarida Gonçalves, apresenta segurança suficiente devido a sua menor extensão territorial e a presença de guardas municipais que realizam o policiamento no local, porém essa segurança não se estende às demais etapas do Parque. 


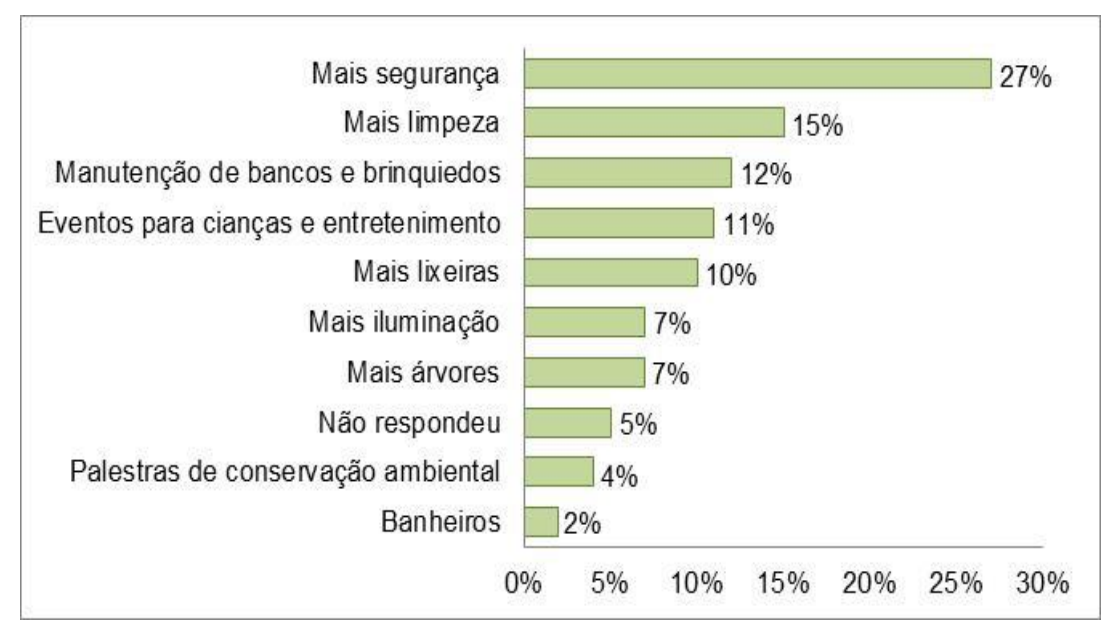

Figura 7. Principais sugestões de melhorias citadas pelos frequentadores do Parque Municipal Ceci Cunha, em Arapiraca-AL

Figure 7. Main suggestions of improvements cited by the users of Ceci Cunha Municipal Park in Arapiraca-AL

Quando analisadas as sugestões de melhorias na infraestrutura, nota-se que $31 \%$ dos entrevistados indicam que deve haver a manutenção de bancos dos brinquedos das crianças, mais iluminação, banheiros e mais lixeiras, ao passo que as questões culturais e ecológicas foram menos recorrentes. Como questão cultural, considerem-se os eventos para as crianças e o entretenimento (11\%), enquanto como questão ecológica, considerem-se a limpeza do ambiente, a promoção de palestras sobre conservação ambiental e o plantio de árvores (26\%).

As sugestões ou reivindicações de melhorias, de modo geral, também foram observadas em outros estudos, como os realizados por Brun et al. (2010), Gomes Júnior (2016) e Zardin et al. (2017), demonstrando que há uma certa tendência de reivindicações de usuários de espaços públicos que buscam melhores lugares, quantitativa e qualitativamente, no meio urbano.

Assim como constatado por Pereira e Simonetti (2012), as sugestões feitas pelos entrevistados para a melhoria de parques refletem a necessidade de mudanças de atitude por parte do órgão gestor desses parques. Entretanto, aponta-se também a necessidade de ações conscientes por parte dos frequentadores, materializadas em atitudes e valores, pois de nada adianta um espaço público planejado e mantido adequadamente, se os usuários não possuírem responsabilidade e sensibilidade ambientais para a manutenção dos mesmos. Neste sentido, ações de educação ambiental podem ser promovidas pelo órgão gestor para auxiliar na sensibilização dos frequentadores, com o intuito de desenvolver a consciência de conservação desse espaço.

De modo geral, nos parques urbanos, os usuários devem ser recepcionados com programas e ações específicas, potencializando o lazer como instrumento de educação social e ambiental, em um espaço público que busque unir e equilibrar o natural, o sociocultural e o transformado (PEREIRA; SIMONETTI, 2012). Nesse sentido, para esses autores, a importância 
da percepção ambiental se dá, principalmente, por ser considerada a precursora do processo que desperta a conscientização do indivíduo em relação às realidades ambientais observadas.

\section{CONCLUSÃO}

Os frequentadores do Parque Municipal Ceci Cunha, em Arapiraca-AL, desempenham usos variados do mesmo. A partir da análise de sua percepção ecológico-conservacionista, verificou-se que a maioria dos usuários apresenta-se preocupada com a conservação e a manutenção do Parque e, por isso, propõem soluções que visam minimizar os pontos negativos desse espaço público, com a finalidade de contribuir com o aumento do número de frequentadores. Além disso, ao considerarem a arborização um elemento relevante, reconhecem que a mesma tanto participa da composição estético-paisagística do local quanto proporciona bem-estar aos citadinos.

Os usuários, ao considerarem o Parque como um importante espaço da malha urbana do município de Arapiraca e expressarem sua percepção a respeito do mesmo, podem nortear as políticas públicas não apenas no que tange a melhorias nesse Parque, mas a qualquer outro espaço público da cidade. Com esse intuito, recomenda-se a realização de palestras/projetos de educação ambiental, que visem suprir a falta de informação e orientação dos frequentadores, maximizando as ações de conservação no Parque.

\section{AGRADECIMENTOS}

Os autores agradecem aos entrevistados que aceitaram participar deste estudo, bem como aos avaliadores pelas contribuições dadas ao manuscrito.

\section{REFERÊNCIAS}

ALMEIDA, C. G.; GÊA, B. C. C.; SIQUEIRA, M. V. B. M. Percepção ambiental da população sobre a arborização urbana do bairro Centro no município de Arealva, São Paulo. Revista da Sociedade Brasileira de Arborização Urbana, Piracicaba, v. 14, n. 3, p. 37-49, 2019.

AMADOR, M. B. M. Percepção da paisagem do Parque Euclides Dourado no município de Garanhuns - PE. Fórum Ambiental da Alta Paulista, v. 8, n. 4, p. 01-14, 2012. 
BARROS, V. S.; MARTINS, C. M.; SANTOS, M. A. S.; REBELLO, F. K.; MONTEIRO, C. W. B.; MESQUITA, I. S. B. Avaliação da organização arbórea e a percepção dos usuários das praças do município de Mocajuba, Estado do Pará, Brasil. Revista da Sociedade Brasileira de Arborização Urbana, Piracicaba, v. 13, n. 3, p. 01-12, 2018.

BRUN, F. G. K.; DOBBERT, L. Y.; SERVOLO-FILHO, H. J.; ZAIA, H. B. A.; SILVA-FILHO, D. F. Percepção dos usuários em relação ao conforto ambiental de duas áreas verdes de Piracicaba - SP. Revista da Sociedade Brasileira de Arborização Urbana, Piracicaba, v. 5, n. 3, p. 5981, 2010.

CARVALHO, J. B. Percepção e relações ambientais dos moradores da comunidade agrícola Palestina no município de Axixá-TO. In: JORNADA DE INICIAÇÃO CIENTÍFICA E EXTENSÃO, 1., 2010, Palmas. Anais... Palmas: Instituto Federal de Educação Ciência e Tecnologia do Tocantins, 2010. p. 31-37.

FERREIRA, L. I. E. P. Parque urbano. Paisagem e Ambiente, São Paulo, v. 1, n. 23, p. 20-33, 2007.

GARVIN, A. Public parks: the key to livable communities. New York/London: W.W. Norton \& Company, 2011.

GIL, A. C. Métodos e técnicas de pesquisa social. 6 ed. São Paulo: Atlas, 2011. 109p.

GOMES JÚNIOR, J. S. Produção e uso do espaço público em Arapiraca, Alagoas: uma avaliação pós-ocupação do Parque Municipal Ceci Cunha e do Bosque das Arapiracas. 2016. 119f. Dissertação (Mestrado em Arquitetura e Urbanismo) - Universidade Federal de Alagoas, Maceió, 2016.

GOMES, M. A. S. Os parques e a produção do espaço urbano. Jundiaí: Paco Editorial, 2013. $176 p$.

GOMES, M. A. S.; SILVA, R. N.; FERREIRA, R. V. Mudanças socioespaciais urbanas em Arapiraca-AL na aurora do século XXI. Espaço \& Geografia, Brasília, v. 18, v. 1, p. 25-53, 2015.

HERZOG, C. P.; ROSA, L. Z. Infraestrutura verde: sustentabilidade e resiliência para a paisagem urbana. Revista LabVerde, São Paulo, v. 1, n. 1, p. 92-115, 2010.

IBGE - INSTITUTO BRASILEIRO DE GEOGRAFIA E ESTATÍSTICA, 2018. Panorama de estimativa populacional - 2018. Disponível em: <https://cidades.ibge.gov.br/brasil/ al/arapiraca/panorama>. Acesso em: 11 jun. 2019.

MARTINEZ, D. I. Representações e percepções sobre ambiente e conservação como subsídio ao Gerenciamento Costeiro Integrado: estudo de caso com grupos sociais da região de Cananéia, litoral sul do Estado de São Paulo. 2012. 174f. Dissertação (Mestrado em Ciências) - Universidade de São Paulo, São Paulo, 2012.

MASCARENHAS, J. C.; BELTRÃO, B. A.; SOUZA JÚNIOR, L. C. (Org.). Projeto cadastro de fontes de abastecimento por água subterrânea: diagnóstico do município de Arapiraca, Estado de Alagoas. Recife: CPRM/PRODEEM, 2005. 13p.

NASIR, R. A.; AHMAD, S. S.; AHMED, A. Z. The relationship of physical activity and human comfort in urban park. Asian Journal of Behavioral Studies, United Kingdom, v. 1, n. 2, p. 3648, 2016. 
PEREIRA, L. F.; SIMONETTI, S. R. A percepção ambiental de frequentadores do Parque Ponte dos Bilhares em Manaus - AM. In: SEMINÁRIO DE PESQUISA EM TURISMO DO MERCOSUL, 7., 2012, Caxias do Sul, Anais... Caxias do Sul: Universidade de Caxias do Sul, 2012.

PINA, J. H. A.; SANTOS, D. G. A influência das áreas verdes urbanas na qualidade de vida: o caso dos Parques do Sabiá e Victório Siquierolli em Uberlândia-MG. Ateliê Geográfico, Goiânia, v. 6, n.1, p. 143-169, 2012.

PIZZIOLO, B. V.; TOSTES, R.; SILVA, K.; ARRUDA, V. M. Arborização urbana: percepção ambiental dos moradores dos bairros Bom Pastor e Centro da cidade de Ubá/MG. Revista Eletrônica em Gestão, Educação e Tecnologia Ambiental-REGET, Santa Maria, v. 18, n. 3, p. 1162-1169, 2014.

ROPPA, C.; FALKENBERG, J. R.; STANGERLIN, D. M.; BRUN, F. G. K.; BRUN, E. J.; LONGHI, S. J. Diagnóstico da percepção dos moradores sobre a arborização Urbana na Vila Estação Colônia - Bairro Camobi, Santa Maria - RS. Revista da Sociedade Brasileira de Arborização Urbana, Piracicaba, v. 2, n. 2, p.11-30. 2007.

SILVA, E. A. P. C; SILVA, P. P. C.; SANTOS, A. R. M.; MOURA, P. V.; SCOCUGLIA, J. B. C.; FREITAS, C. M. S. M. Emoções e sentimentos nos espaços de lazer da cidade. Pensar a Prática, Goiânia, v. 16, n. 1, p. 85-100, 2013.

SILVA, R. N.; GOMES, M. A. S. Comparação quali-quantitativa da arborização em espaços públicos da cidade de Arapiraca-AL. Revista da Sociedade Brasileira de Arborização Urbana, Piracicaba, v. 8, n. 2, p. 104-117, 2013.

SILVA, R. N.; GOMES, M. A. S. Parques urbanos em Alagoas: Caracterização e análise no âmbito da produção do espaço. Revista Percurso - NEMO, Maringá, v. 2, n. 1, p. 107-133, 2010.

SILVA, T. S.; CÂNDIDO, G. A.; FREIRE, E. M. X. Conceitos, percepções e estratégias para conservação de uma estação ecológica da caatinga nordestina por populações do seu entorno. Sociedade \& Natureza, Uberlândia, v. 21 n. 2, p. 23-27, 2009.

ZARDIN, M. C.; OLIVEIRA, J. D. de.; ARTHUSO, J. P.; BIONDI, D. Perfil e percepção dos frequentadores do Parque Municipal São Lourenço de Curitiba - PR. Revista da Sociedade Brasileira de Arborização Urbana, Piracicaba, v. 12, n. 3, p. 37-50, 2017. 